\title{
How the possibility of a fight-back strategy affects the consequences of a sanctions regime
}

\author{
Mohammad Sadegh Karimi \\ Department of Energy Engineering, \\ Sharif University of Technology, Iran \\ mkarimi@energy.sharif.edu \\ ORCID 0000-0002-8768-1106
}

\author{
Abbas Maleki \\ Department of Energy Engineering, \\ Sharif University of Technology, Iran \\ maleki@sharifedu \\ ORCID 0000-0003-2904-4587 \\ *Corresponding author
}

\author{
Asieh Haieri Yazdi \\ Centre for Energy, Petroleum, and Mineral Law and Policy \\ (CEPMLP), School of Social Sciences, University of Dundee, UK \\ 2391480@,dundee.ac.uk \\ ORCID 0000-0002-2116-3146
}

\begin{abstract}
Sanctions imposed by a country against another country are considered as a foreign policy tool. Many studies have investigated different aspects of sanctions including the efficacy of sanctions to alter the target country's behaviour. However, the effects of a potential fight-back strategy adopted by a target country have been discussed rarely. In this paper, the outcomes of a possible fight-back strategy are simulated using game theoretical analysis. To find the matching state of game theory and sanction regimes, we have conducted a critical and systematic review of 12 sanctions, from 1950 to 2012. The results show that the capability of a target country to implement fight-back strategies provides the opportunity to change the sender's expected outcomes. It also makes the occurrence of future sanctions less probable or even less feasible.
\end{abstract}

Keywords: sanctions, game theory, fight-back strategy, rival country, Iran sanctions.

JEL Classification: C73, F51, N45 


\section{INTRODUCTION}

Sanctions are being used as a tool of foreign policy by powerful states, international and intergovernmental institutions. Sometimes sanctions are also considered as alternatives for military actions. In addition to some individual states, the United Nations Security Council (UNSC) has used sanctions in order to establish peace and prevent war around the world. The broad use of sanctions in international relations has attracted scholars from different areas of expertise to study them as a phenomenon, their outcomes, their effectiveness, and their moral and legal modality.

While comprehensive insights about the effects of a specific sanction on the interests of a target country, and consequently, its behaviour are necessary for both sender and target countries, both sides also seek to be knowledgeable about any potential countermeasures in other areas of common interests, their extents and how they will affect the results of the imposed sanctions. In fact, the political policy reaction of a target country is not limited to its decision on whether to continue its provocative actions or to comply with the sanctions regime and withdraw. That is the reason why, aside from continuation or halting the contested policy -hereafter referred to as "the primary" area of interests-, both sender and target countries require sufficient knowledge about possible countermeasures and how they are able to influence their interests - hereafter referred to as "the secondary" area of interests.

There seems to be many secondary areas of interest here as well, like access to the free market, or the security policy, the oil market or the geopolitics of the sender's allied countries etc. In addition, the target countries are expected to use their ability to strike the sender's interests in those areas and thus impress the outcome of the sanctions for their own benefits. However, reviewing the sanctions practices show that they mostly end up when the target country draws back or loses the game. Hence, a critical discussion is needed to show why and how the possibility of a countermeasure is able to change the outcome of a sanctions regime and how the expected outcome will change if there is no such a possibility. This includes the specification of the circumstances under which a fight-back strategy (a strategy taken as a countermeasure) can be helpful for a target country as well as the conditions under which a potential fight-back strategy may not be effective.

\section{LITERATURE REVIEW}

The issues mentioned in the previous section have not been adequately addressed in the sanction's literature. The studies considering sanctions may be categorized in three main groups: historical, empirical and theoretical studies.

1) Historical studies discuss many different sanction cases, the motive behind them, and the aims, consequences and impacts of the sanctions (Hufbauer, Schott, \& Elliott, 2007; Morgan, Bapat, \& Kobayashi, 2014). Some of these studies have resulted in codified and cohesive data banks of sanction cases (Hufbauer et al., 2007; Morgan et al., 2014; Peksen, 2019; Portela, 2016; Rapelanoro \& Bali, 2020; Tyll, Pernica, \& Arltová, 2018; UN Targeted Sanctions Qualitative Database, 2014).

2) Using the data banks mentioned above, empirical studies investigate the relationship between different parameters in sanction cases and test their assumptions about the effectiveness of the sanctions and other factors influencing the success of a sanctions regime (Hellquist, 2016; Hufbauer et al., 2007; Jeong, 2018; Jing, Kaempfer, \& Lowenberg, 2003; Kaempfer \& Lowenberg, 2007; Kavakli, Chatagnier, \& Hatipoğlu, 2020; Lam, 1990; Lektzian \& Souva, 2001; Lohmann, 2016; Veebel \& Markus, 2018b; Whang, Mclean, \& Kuberski, 2013). Even the effect of sanctions on the energy efficiency of the target country has been discussed. (Chen, Fu, Zhao, Yuan, \& Chang, 2019)

3) Theoretical studies investigate the sanctions as a general issue and try to anticipate the results and outcomes of sanctions and determine the conditions under which these forecasts are valid. The 
main group of the theoretical studies of sanctions use game theory as a useful framework for analyzing the reciprocal effects of the actions of different countries and international players (Brown, 2019; Dong \& Li, 2018; Eaton \& Engers, 1992, 1999; Lacy \& Niou, 2004; McCormack \& Pascoe, 2015; Morgan \& Bapat, 2003; Rapelanoro \& Bali, 2020; Shadiqi \& Pradiptyo, 2011; Simon, 1995; Taehee Whang, 2010; Tsebelis, 1990; Whang \& Kim, 2015). In these kinds of studies, the whole entity of a nation-state is considered as a rational player which seeks to maximize its interests regarding the other players' actions.

Game theoretic approach has been utilized to anticipate the outcome of a sanction regime in many different settings (Simon, 1995; Tsebelis, 1990). These settings include:

- the structure of the game which is either simultaneous or sequential (Eaton \& Engers, 1992; Taehee Whang, 2010)

- the incomplete information (Eaton \& Engers, 1999)

- whether the threat to sanction is a choice or not (Afesorgbor, 2019; Lacy \& Niou, 2004)

- mixed strategy analysis (Shadiqi \& Pradiptyo, 2011)

- players' perception (Whang \& Kim, 2015)

- repetition of the game (McCormack \& Pascoe, 2015; Veebel \& Markus, 2018a)

- players in addition to/except the sender and the target (Dong \& Li, 2018; McLean \& Whang, 2010; Morgan \& Bapat, 2003)

- the power of the targeted country (Brown, 2019)

Game theory and some other methods have also been fruitful in explaining some parameters' effect on the results of a sanction episode. These parameters include:

- the importance of a sanction episode (Drezner, 1999)

- the cost of sanctions for the sender (Dong \& Li, 2018; Whang \& Kim, 2015)

- the stability and power of the leaders in the target country (Spaniel \& Smith, 2015)

- the power of the military force in the target country (McCormack \& Pascoe, 2015)

- the economic and political relations between the two countries (Taehee Whang, 2010)

- the behavior of third parties (Han, 2018)

- the effects of a countermeasure on individuals in both parties (Banse, Duric, Götz, \& Laquai, 2019), or on the outcome of the game (Saparaliyev, Mokin, Movkebayeva, Saiymova, \& Mustafina, 2019; Veebel \& Markus, 2018a)

- the cost of sanctions on the target (Bimbetove et al., 2019; Dong \& Li, 2018; Gharibnavaz \& Waschik, 2018; Salman, Shin, \& Shin, 2019)

- the internal dynamics of both countries and the role of the opposition party (Onder, 2020)

The intensity of sanctions imposed on controversial policies of target states has been also discussed within public choice framework (Kaempfer \& Lowenberg, 1988).

As it is observed in the above review of sanctions research, not many studies have discussed the role of countermeasures in sanctions regime. In most sanctions models and studies the target country can only choose between stopping its offensive policy and continuing it with sanctions being imposed. The novelty of this paper is that it distinguishes another item in the toolbox of the target country in addition to those two common choices, named "fight-back" strategy. It means "to offend the interests of the sender in an area of interest other than the subject of the sanctions".

Correspondingly, in common sanction game models, the sanctioning country's pay-off includes the political gain/loss due the stop/continuation of the target country's disagreeable policy and, only in some researches, the economic costs of sanctions (Namely, the primary area of interest). However, this paper recognizing the "fight-back" strategy, will show that the sender may be offended due to the target's probable 
countermeasures in some other areas of interest (Namely the secondary area of interest). For example, in the case of the United States' sanctions against Iran, the primary area of interest is Iran's nuclear activities. Iran had the option to stop its nuclear activities or proceed its nuclear expansion. In addition, oil market is the secondary area of interest for Iran and the U. S., because the oil market is crucial for both countries, the former as an oil exporter and the latter as a net oil importer. In this regard, Iran had the option to disrupt the oil market and decrease the utility of the sender country.

In summary, the theoretical sanctions' studies have not included the possibility of a counteraction by the target country which may strike the sender country's interests. On the contrary, this paper includes the counteraction option and compares two games: one in which the target does not have the option to fightback and another in which the target has this option. By this comparison, it will, for the first time, be understood that what will happen if the target country is powerful enough to offend the sender in another area of interest and will the sender, in the first place, initiate sanctions game with such a target or not.

This shortcoming of previous theoretical research on sanctions will be addressed in this work. So, the option of fighting back and offending the sender is given to the target country. For the purpose of this paper, the main question is modeled theoretically using game theory and the results are compared with and evaluated by the real sanction cases. The rest of the paper is organized as follows. Section two describes the structure of the game model including the players, their pay-off functions, their strategies and the equilibria. In section three, twelve cases of sanctions are summarized and their outcomes and other parameters including the possibility of countermeasures are discussed and compared within the theoretical results. Section four states the policy implications and provides a conclusion.

\section{THE STRUCTURE OF THE GAMES}

To address the main question about how the possibility of a fight-back strategy may affect a sanction's outcome, two games are discussed below. In the first game (the base game) the target country does not have the possibility to fight-back while in the second game (the aggressive game) it is able to implement such a strategy. Next, the equilibria of these two games are compared and the theoretical conclusion is reached.

\subsection{The base game}

The assumptions for the base game are as follows:

1. Two players: Sender $(\mathrm{S})$ and Target $(\mathrm{T})$

2. Simultaneous move game

3. Perfect information

4. Infinitely repeated game

5. Discount factors of future utilities for the two players are $\delta_{S}$ and $\delta_{T}$

6. Sender's strategies:

a. Sanction (S)

b. Not sanction $(\mathrm{N})$

7. Target's strategies:

a. Pursue $(\mathrm{P})$

b. Withdraw (W)

8. The game starts from a situation in which no contested policy has embarked on and no sanctions have been introduced. In other words, the first strategy of the sender is "not sanction (N)" and the target's first strategy is "withdraw (W)".

9. Players' pay-offs in each repetition of the game are shown in Table 1 
Pay-offs in the base game

\begin{tabular}{|c|c|c|c|}
\hline \multirow{2}{*}{\multicolumn{2}{|c|}{}} & \multicolumn{2}{|c|}{ Target } \\
\cline { 3 - 4 } \multicolumn{2}{|c|}{} & Withdraw (W) & Pursue $(\mathrm{P})$ \\
\hline \multirow{2}{*}{ Sender } & Sanction (S) & $U_{S}-C_{S},-C_{T}$ & $-C_{S}, U_{T}-C_{T}$ \\
\cline { 2 - 4 } & Not Sanction (N) & $U_{S}, 0$ & $0, U_{T}$ \\
\hline
\end{tabular}

In Table $1, U_{S}$ is the sender's utility when pursuit of the contested primary policy is ceased and $U_{T}$ is the target's utility if it pursues the disputed policy. In addition, $C_{i}$ is the cost of sanctions imposed for the player $i .^{1}$ Thus, the total pay-off of player $i$ related to the contingent plan it has chosen is:

$$
\pi^{i}=\sum_{t=1}^{\infty} \pi_{t}^{i} \delta_{i}^{t-1}
$$

where $t$ is the counter of time-steps.

Recent studies on modeling sanctions using game theory have not considered sanction games as infinite games. So the alternative method to model such a situation is to consider it as a one-time game, either simultaneous or sequential, as in (Brown, 2019; Dong \& Li, 2018; Eaton \& Engers, 1999; Lacy \& Niou, 2004; McCormack \& Pascoe, 2015; Morgan \& Bapat, 2003; Shadiqi \& Pradiptyo, 2011; Simon, 1995; Taehee Whang, 2010; Tsebelis, 1990). This method is more straightforward to be solved and the equilibria in such models are computed without difficulty.

In spite of the fact that one-time game models are simple to solve, their assumptions are unreal and as simple. Instead, infinitely repeated games are more precise, although more complicated to solve. Because relations between countries continue to exist as long as the countries exist which means to "infinity", and it seems that any modeling should consider the fact that the game between countries does not come to an end. The game played in real world is not played like this: "in a unique time interval, the sender and the target - simultaneously or sequentially - choose their strategy, take their pay-offs and end the game". Rather, countries are constantly and continuously choosing their own status and strategy in different time frames.

Even sustainable situations, such as a situation where there is neither an imposed sanction nor a controversial policy, may alter at any time in the future. A stable state, in turn, is the repeated version of the decisions related to that state in a long-term time frame. In other words, countries continuously or on a yearly, monthly or even daily basis, determine their approach and strategy towards another country or regarding an issue. When the relation between two countries is considered as "stable" it means that they both are continuously choosing that "stable" status and at any time in future one of them may choose not to keep this strategy and start a "destabilizing" strategy. Thus, as long as countries are choosing their approach and strategy, they are in a game and they are playing it, although they may seemingly be inactive. That is why the sanctions games might be assumed as infinitely repeated games.

However, considering international relations as infinitely repeated games has its limitations. First, it cannot be helpful in situations where a "regime change" takes place or a nation-state disappears/emerges due to national collapse or annexation to/occupation by another country. Second, the factual game being played between countries is not the same game at every time step. The choices, the corresponding pay-offs and even the new players to come, alter especially during longer time frames. That is why, when establishing

\footnotetext{
${ }^{1}$ Hereafter we define $\mathrm{kT}$ and $\mathrm{kS}$ as $\mathrm{kT}=\mathrm{UT} / \mathrm{CT}$ and $\mathrm{kS}=\mathrm{US} / \mathrm{CS}$
} 
an infinitely repeated game, it should be noticed that countries, at a specific time step, may not be playing absolutely the same game as the one they played in another time step. Finally, the internal dynamics of a country is neglected in this approach. In other words, it is assumed that the attitude and mentality of a country and its leaders are constant during time. Thus, the pay-off function of an infinitely repeated game is set to be constant. However, in reality, priorities and thus the pay-off function of a country and its leaders may transform.

Despite these drawbacks, sanctions can be simulated using infinitely repeated games. Due to the fact that we can make some assumptions:

1. No regime change will occur

2. The structure of the game especially the actions and corresponding pay-offs are constant

3. The countries' attitudes and worldview are constant

\subsection{The aggressive game}

The structure of the aggressive game is like that of the base game, with the exception that the target possesses the possibility of a countermeasure to strike the sender in an area other than the controversial policy. In the design of the utility function of the two players, it is also assumed that this fight-back strategy (F) only involves disutility for the two players and does not bring about any benefits itself. In other words, it is assumed that the sanctioned party, by imposing value-deprivation on itself through retaliation, tries to impose a (possibly bigger) disutility on the sender to dissuade it from imposing sanctions and, as a result, to obtain greater pay-off. Therefore, a countermeasure is a strategy that is not implemented under normal circumstances, or without an imposed or threatening sanction because of its costly nature. The players' payoffs in each period of the repeated game in the aggressive game, is shown in Table 2

Pay-offs in the aggressive game

\begin{tabular}{|c|l|c|c|c|}
\hline \multicolumn{2}{|c|}{} & \multicolumn{3}{|c|}{ Target } \\
\cline { 3 - 5 } \multicolumn{2}{|c|}{} & Withdraw (W) & Pursue (P) & Fight-back (F) \\
\hline \multirow{3}{*}{ Sender } & Sanction (S) & $U_{S}-C_{S},-C_{T}$ & $-C_{S}, U_{T}-C_{T}$ & $-C_{S}-F_{S}, U_{T}-C_{T}-F_{T}$ \\
\cline { 2 - 5 } & $\begin{array}{l}\text { Not } \\
\text { Sanction (N) }\end{array}$ & $U_{S}, 0$ & $0, U_{T}$ & $-F_{S}, U_{T}-F_{T}$ \\
\hline
\end{tabular}

\subsection{The equilibria}

To find the equilibria, it is essential to consider the various possible contingent plans and each player's incentive to deviate from its own plan using "the one-step deviation property". In the following, some equilibria for the two games are to be introduced. These equilibria are not necessarily all possible cases of the two games. However, according to the reciprocal and reactive nature of the sanctions game, it has been tried to select the best and most probable contingent plans that can properly illustrate the reality of the behavior of states in international relations and in the game of sanctions. Hence, the contingent plans incorporated are reactive plans, in which each player specifies its reaction to the other player's action on the previous time-step. So, given the previous choice of its opponent, a player's choice is determined. For example, in a contingent plan named Brave (B), the sender stops the sanctions (chooses $\mathrm{N}$ ) every time it observes that the target has withdrawn (chosen $\mathrm{W}$ ) in the previous time-step. A Brave (B) sender sanctions (chooses S) every time it observes that the target has pursued its controversial policy in the previous timestep. Likewise, other contingent plans for both players have been defined and are as follows. 
Contingent plans defined for both players in both games

\begin{tabular}{|c|c|c|c|}
\hline Game & Player & Plan's name & Definition \\
\hline Base Game & Sender & Brave (B) & $a_{S, t}=\left\{N\right.$ if $a_{T, t-1}=W$ S if $a_{T, t-1}=P$ \\
\hline Base Game & Target & Revenger (R) & $a_{T, t}=\left\{W\right.$ if $a_{S, t-1}=N$ P if $a_{S, t-1}=S$ \\
\hline Aggressive Game & Sender & Brave (B) & $\begin{array}{c}a_{S, t}=\left\{N \quad \text { if } a_{T, t-1}=W S \text { if } a_{T, t-1}\right. \\
=P \text { or } F\end{array}$ \\
\hline Aggressive Game & Sender & Revenger (R) & $\begin{array}{l}a_{S, t}=\left\{N \text { if } a_{T, t-1}\right. \\
=W \text { or } P S \quad \text { if } a_{T, t-1}=F\end{array}$ \\
\hline Aggressive Game & Sender & Coward $(\mathrm{C})$ & $\begin{array}{l}a_{S, t}=\left\{N \text { if } a_{T, t-1}\right. \\
=W \text { or } F S \quad \text { if } a_{T, t-1}=P\end{array}$ \\
\hline Aggressive Game & Target & Revenger (R) & $a_{T, t}=\left\{W\right.$ if $a_{S, t-1}=N$ P if $a_{S, t-1}=S$ \\
\hline Aggressive Game & Target & Aggressive (A) & $a_{T, t}=\left\{W\right.$ if $a_{S, t-1}=N$ F if $a_{S, t-1}=S$ \\
\hline Aggressive Game & Target & Coward $(\mathrm{C})$ & $a_{T, t}=\left\{P\right.$ if $a_{S, t-1}=N$ W if $a_{S, t-1}=S$ \\
\hline Aggressive Game & Target & Brave (B) & $a_{T, t}=\left\{P\right.$ if $a_{S, t-1}=N$ F if $a_{S, t-1}=S$ \\
\hline
\end{tabular}

In Table 3, $a_{S, t}$ is the action of the sender in time-step $t$ and $a_{T, t}$ is the action of the target in timestep $t$.

The only equilibrium of the base game is presented in Table 4.

Table 4

The base game's equilibrium using reactive contingent plans

\begin{tabular}{|c|c|c|c|c|c|}
\hline \multicolumn{2}{|c|}{ Sender } & \multicolumn{2}{|c|}{ Target } & \multirow{2}{*}{ Outcome } & Criterion \\
\cline { 1 - 3 } $\begin{array}{c}\text { Strategy } \\
\text { name }\end{array}$ & Strategy & $\begin{array}{c}\text { Strategy } \\
\text { name }\end{array}$ & Strategy & NW & $\delta_{T} \geq k$ \\
\hline Brave (B) & $\begin{array}{c}a_{S, t}=\left\{N \text { if } a_{T, t-1}\right. \\
=W S \text { if } a_{T, t-1}=P\end{array}$ & $\begin{array}{c}\text { Revenger } \\
(\mathrm{R})\end{array}$ & $\begin{array}{c}a_{T, t}=\left\{W \text { if } a_{S, t-1}\right. \\
=N P \text { if } a_{S, t-1}=S\end{array}$ & N \\
\hline
\end{tabular}

In the above equilibrium, the sender declares that if the target has not pursued the disputed policy in the previous round, sender in turn will not impose a sanction, but if the contested policy has been pursued in the previous time-step, the sanctions will be imposed. On the other side, the target announces that it would not pursue the disputed policy if the sanctions were not imposed in the previous round, but if it observes that the sender had implemented sanctions in the previous round, target would pursue the controversial policy in the following round of the game. This equilibrium's (steady state) outcome is a situation in which the target does not pursue its contested policy and the sender does not put sanctions in place (showed by NW).

Table 5 shows the equilibria of the aggressive game.

It is observed that by adding the new assumption that the target has the ability to counteract, three equilibria will be added to the base game's equilibrium. In addition, two of the new equilibria lead to a situation in which no sanctions exist while the controversial policy is also pursued (showed by NP). A comparison of the equilibria of these two games includes the following results:

1. The possibility of counteracting in some situation can be used to shift the equilibrium from NW (an equilibrium without sanctions and with stopped contested policy which is mostly favorable for the sender) to the NP (an equilibrium without sanctions and with continued contested policy which is mostly favored by the target). In other words, if the sanctioned country does not have the possibility to fight-back, there is essentially no possibility of reaching an agreement in which target 
is not sanctioned, and can pursue the disputed policy. Despite, the power of counteracting may lead to a better deal for the target country. Of course, having the ability to counteract does not necessarily lead to a change in the equilibrium and in realization of the target's benefits, and it will still be possible to reach to an equilibrium of stopping both the sanctions and the controversial policy (NW).

Table 5

The aggressive game's equilibria using reactive contingent plans

\begin{tabular}{|c|c|c|c|c|c|}
\hline \multicolumn{2}{|r|}{ Sender } & \multicolumn{2}{|r|}{ Target } & \multirow[b]{2}{*}{ Outcome } & \multirow[b]{2}{*}{ Criterion } \\
\hline $\begin{array}{l}\text { Strategy } \\
\text { name }\end{array}$ & Strategy & $\begin{array}{l}\text { Strategy } \\
\text { name }\end{array}$ & Strategy & & \\
\hline Brave (B) & $\begin{array}{l}a_{S, t}=\left\{N \text { if } a_{T, t-1}\right. \\
=W S \text { if } a_{T, t-1}=P\end{array}$ & $\begin{array}{l}\text { Revenger } \\
\text { (R) }\end{array}$ & $\begin{array}{l}a_{T, t}=\left\{W \text { if } a_{S, t-1}\right. \\
=N \text { P if } a_{S, t-1}=S\end{array}$ & NW & $\delta_{T} \geq k$ \\
\hline Brave (B) & $\begin{array}{l}a_{S, t}=\left\{N \quad \text { if } a_{T, t-1}\right. \\
=W S \text { if } a_{T, t-1} \\
=P \text { or } F\end{array}$ & $\begin{array}{l}\text { Aggressive } \\
\text { revenger } \\
\text { (A) }\end{array}$ & $\begin{array}{l}a_{T, t}=\left\{W \text { if } a_{S, t-1}\right. \\
=N F \text { if } a_{S, t-1}=S\end{array}$ & NW & $\begin{array}{l}\frac{F_{T}}{C_{T}} \delta_{T}^{2} \\
+\delta_{T}-k_{T} \\
\geq 0\end{array}$ \\
\hline $\begin{array}{l}\text { Revenger } \\
\text { (R) }\end{array}$ & $\begin{array}{l}a_{S, t}=\left\{N \text { if } a_{T, t-1}\right. \\
=W \text { or } P S \quad \text { if } a_{T, t} \\
=F\end{array}$ & Coward (C) & $\begin{array}{l}a_{T, t}=\left\{P \text { if } a_{S, t-1}\right. \\
=N W \text { if } a_{S, t-1}=S\end{array}$ & $\mathrm{NP}$ & $\delta_{S} \leq \frac{1}{k_{S}}$ \\
\hline $\begin{array}{l}\text { Revenger } \\
\text { (R) }\end{array}$ & $\begin{array}{l}a_{S, t}=\left\{N \text { if } a_{T, t-1}\right. \\
=W \text { or } P S \quad \text { if } a_{T, t} \\
=F\end{array}$ & Brave (B) & $\begin{array}{l}a_{T, t}=\left\{P \text { if } a_{S, t-1}\right. \\
=N F \text { if } a_{S, t-1}=S\end{array}$ & NP & - \\
\hline
\end{tabular}

The implication of this result is that whenever a sanctioned country is not powerful enough to retaliate and offend the interests of the sanctioner, it can be predicted that sanctions will be successful in stopping the target country from pursuing its contested policy. In contrast, whenever a sanctioned country has the capability to retaliate, for example by disrupting the oil market or by declaring war against one of the sanctioner's allies, we cannot certainly predict that the sanctions will be successful. In this case, depending on some other circumstances, both success and failure of the sanctions are possible. This means that if a sanctioned country prepares a retaliation capability for itself, for example a military base near the borders of a sanctioner's ally, it can expect that the result will change, the sanctions may be lifted and it can pursue its favored policy which has been the reason for sanctions. But if it does not prepare such a capability to retaliate, the model suggests that it has no way to change the result and sanctions will keep being in place until that target country stops its favorable policy.

2. Both the sender and the target can choose to be a "starter" or a "non-starter". A starter sender reacts by sanctions $(S)$ if it observes the target has chosen to pursue the disputed policy $(\mathrm{P})$ in the previous round but a non-starter sender chooses not to sanction $(\mathrm{N})$ in the same situation. On the other side a starter target reacts by pursuing the contested policy $(\mathrm{P})$ if it observes the sender has chosen not to sanction $(\mathrm{N})$ in the previous round but a non-starter target chooses not to pursue the disputed policy (W) in the same situation. It is observed that the NW equilibrium appears only if the target is a non-starter and the sender is a starter and the NP equilibrium appears only if the sender is a non-starter and the target is a starter. If both players choose to be a starter (which seems to be the case in most sanction episodes), or both choose to be a non-starter there will be no equilibria. This suggests that no steady state balance, in which the sanctions are imposed and the contested disputed policy also continues to be pursued, would be observed in reality. It also suggests 
that for reaching an agreement (i.e. an equilibrium) one and only one player should choose not to be a starter. Whoever chooses to be a non-starter will literally be "the loser" of the game.

The implication of this result is that whoever chooses not to react to the other country's action will be the loser. For one side, the model suggests that whenever a sanctioner, e.g. U.S, observes that the target country, e.g. Iran, keeps its contested policy, e.g. expanding nuclear program, it must put sanctions into force, otherwise U.S will lose (which means Iran keeps the nuclear program). On the other side, whenever Iran observes a relaxation or lift in the sanctions regime, it should restart its nuclear expansion plan, otherwise Iran will lose (which means it will have to stop its nuclear program). As a result, the first one who chooses to retreat will lose the game. And if no one does so, there will be no agreement. It also implies that in any stable agreement (which should be the equilibrium of the game), one and only one of the two parties have chosen to retreat.

3. When a target country starts to pursue a disputed policy, in an analogy to cash flow analysis, sanctioning can be like an investment for the sender. The investor (the sender) has two options on the table. First, not to deal with the contested disputed policy and remain in the equilibrium of "no sanctions with the disputed policy pursued" (NP). This option does not provide the investor with any special benefit nor any disadvantage. This action is considered as an equilibrium in which, by definition, no player has the incentive to change its strategy. The second option is to deviate from the existing equilibrium, hoping to gain a greater return after a period. Deviating from the equilibrium behavior is considered as disutility (or capital cost in investment). That is, a sanctioner who violates equilibrium behavior is exposed to some expenses but hopes to return the investment by changing the target's strategy and achieving a "no sanctions with no disputed policy" balance $(\mathrm{NW})$. As the capital investment (sanctions) go on and no signs of a change in the target's behavior are observed, the sender concludes that the investment is mistaken and halts the flow of investment (i.e. the imposition of sanctions). Despite, as soon as the target's behavior changes, the payback period begins.

This implies that considering sanctions as an investment explains why sanctioners initiate a series of sanctions. The reason is that they accept the costs of sanctions in the hope of future returns in terms of stopping the undesirable policy of the target country. The sooner the target country stops its disputed policy, the more feasible is a sanctions regime. It also explains why the target has the tendency to persist and tolerate the costs of the sanctions in order for the sender to retreat. The reason is that target's persistence, reduces the attractiveness of a "sanction investment" for the sanctioner.

4. The magnitude of the counteraction costs does not have any effect on the games' equilibria. In other words, it does not matter whether countermeasures are very costly for the sender or not. In any case, the achievement of the NP or NW equilibrium is subject to the two players' choice to be a starter or not and the equilibrium criteria have nothing to do with the proportion or magnitude of countermeasures' costs.

The implication of this result is that no matter how costly a countermeasure is for the sanctioner, the very existence of the possibility to countermeasure makes the difference. A target country with no option to retaliate is doomed to lose the game and stop its desired policy. Despite, a target country with the option to retaliate, be it large and costly for the sanctioner or not, can have the hope to win the game and keep its desired policy.

5. The implication of the equilibrium criteria in the base game (Table 4) is that in order to achieve the "no sanctions with no disputed policy" agreement (NW), the value of the future benefits for the target must be greater than the ratio of the value of maintaining the disputed policy to the costs of the sanction. This means that, at least, the sanction costs must be greater than the desirability of pursuing the disputed policy. Otherwise, given the fact that $\delta_{t}$ must be less than one, there would 
essentially be no possibility for a "no sanctions with no disputed policy" agreement (NW). This means the sender would have to introduce severe sanctions if it wants to move the balance of the game from NP to NW. With small, low-cost sanctions, it cannot fulfill the NW equilibrium condition.

This equilibrium condition $\left(\delta_{T} \geq \frac{U_{T}}{C_{T}}\right)$ also implies that if a target country is forethoughtful and weighs future gains almost as important as short term benefits (larger $\delta_{T}$ ), less costly sanctions will suffice to prevent it from continuing its contested policy. On the contrary, if a target regime only considers its short term interests (smaller $\delta_{T}$ ), the sanctions must be more costly in order to make them stop their disputed policy. For example, a country which wants to be at least a regional power in the next decades, will change its behavior with less costly sanctions. But a temporary regime in a geopolitically weak region with no foresight of becoming a magnificent power, will stop its policies only when the costs of sanctions are relatively high.

This conclusion is more precise than that of the previous studies which have considered the costs of sanctions for the target country. They mostly have argued that the cost of the sanctions must be high enough to make that sanctions' regime effective. (Hufbauer, Schott, and Elliott 2007; Whang and Kim 2015) But here, in addition to their conclusion, we distinguished between different countries and showed a cost threshold before which the sanctions will be ineffective. We suggested a criterion to investigate whether that threshold is passed or not.

\section{EMPIRICAL EVIDENCE}

Twelve cases have been reviewed and documented in a detailed case study of the history of events and developments in various instances of sanctions. Regarding the fact that these cases were not codified and discussed from the point of view of countermeasures and their realization, the chronological history of their key events were also studied. In this way, it was possible to check the capability of counteracting over the sanctions during their assigned period and their successful realization. According to authors' classification of sanction cases, these twelve cases are summarized in Table 6 .

Table 6

Summary of the studied cases regarding the possibility of a fight-back strategy

\begin{tabular}{|c|c|c|c|c|c|c|c|c|}
\hline Target & $\begin{array}{l}\text { Start } \\
\text { year }\end{array}$ & $\begin{array}{l}\text { Last } \\
\text { action } \\
\text { taken }\end{array}$ & $\begin{array}{c}\text { Contested } \\
\text { policy }\end{array}$ & $\begin{array}{c}\text { Fight-back } \\
\text { strategy }\end{array}$ & Current status & $\begin{array}{c}\text { Duration } \\
\text { since last } \\
\text { action } \\
\text { (years) } \\
\end{array}$ & $\begin{array}{l}\text { Sustained } \\
\text { equilibrium }\end{array}$ & $\begin{array}{c}\text { Continued } \\
\text { in another } \\
\text { case }\end{array}$ \\
\hline Sudan & 1989 & 2011 & $\begin{array}{l}\text { Human } \\
\text { rights }\end{array}$ & No & $\begin{array}{c}\text { No sanctions- No } \\
\text { contested policy } \\
\text { (NW) }\end{array}$ & 6 & Yes & No \\
\hline $\begin{array}{l}\text { South } \\
\text { Africa }\end{array}$ & $\begin{array}{c}1960 \\
- \\
1985 \\
\end{array}$ & 1998 & $\begin{array}{l}\text { Human } \\
\text { rights }\end{array}$ & No & $\begin{array}{c}\text { No sanctions- No } \\
\text { contested policy } \\
(\mathrm{NW})\end{array}$ & 19 & Yes & No \\
\hline Iraq & 1980 & 1990 & Terrorism & No & $\begin{array}{c}\text { Sanctions- } \\
\text { contested policy } \\
\text { pursued (SP) }\end{array}$ & - & No & In Iraq 1990 \\
\hline Syria & 1986 & 2006 & $\begin{array}{c}\text { Terrorism } \\
\text { and chemical } \\
\text { weapons } \\
\end{array}$ & No & $\begin{array}{c}\text { Sanctions- } \\
\text { contested policy } \\
\text { pursued }(\mathrm{SP})\end{array}$ & - & No & In Syria 2011 \\
\hline Syria & 2011 & 2017 & $\begin{array}{l}\text { Human } \\
\text { rights }\end{array}$ & No & $\begin{array}{c}\text { Sanctions- } \\
\text { contested policy } \\
\text { pursued (SP) }\end{array}$ & 1 & No & No \\
\hline
\end{tabular}




\begin{tabular}{|c|c|c|c|c|c|c|c|c|}
\hline Libya & $\begin{array}{c}1978 \\
- \\
1992\end{array}$ & 2003 & $\begin{array}{l}\text { Terrorism } \\
\text { and aircraft } \\
\text { attack }\end{array}$ & $\begin{array}{c}\text { Expulsion of } \\
\text { foreign } \\
\text { workers } \\
\text { Military } \\
\text { action and } \\
\text { threat } \\
\end{array}$ & $\begin{array}{c}\text { No sanctions- No } \\
\text { contested policy } \\
\text { (NW) }\end{array}$ & 11 & Yes & No \\
\hline Libya & 2011 & 2012 & $\begin{array}{l}\text { Human } \\
\text { rights }\end{array}$ & $\begin{array}{c}\text { Military } \\
\text { threat to } \\
\text { Europe }\end{array}$ & $\begin{array}{c}\text { No sanctions- No } \\
\text { contested policy } \\
\text { (NW) }\end{array}$ & 5 & Yes & No \\
\hline Iran & 1979 & 1983 & U.S. embassy & $\begin{array}{l}\text { Oil export } \\
\text { cuts }\end{array}$ & $\begin{array}{c}\text { No sanctions- No } \\
\text { contested policy } \\
\text { (NW) }\end{array}$ & 34 & Yes & No \\
\hline Iran & $\begin{array}{c}1984 \\
- \\
2006\end{array}$ & 2015 & $\begin{array}{l}\text { Proliferation } \\
\text { and nuclear }\end{array}$ & $\begin{array}{l}\text { Oil export } \\
\text { cuts } \\
\text { Missile test } \\
\text { and threat }\end{array}$ & $\begin{array}{c}\text { No sanctions- No } \\
\text { contested policy } \\
\text { (NW) }\end{array}$ & 2 & Yes & No \\
\hline Iraq & 1990 & 2003 & $\begin{array}{l}\text { Weapons of } \\
\text { mass } \\
\text { destruction }\end{array}$ & $\begin{array}{l}\text { Oil export } \\
\text { cuts }\end{array}$ & $\begin{array}{c}\text { No sanctions- No } \\
\text { contested policy } \\
\text { (NW) }\end{array}$ & 14 & Yes & No \\
\hline Cuba & 1960 & 2011 & $\begin{array}{l}\text { Human } \\
\text { rights } \\
\text { Communism }\end{array}$ & $\begin{array}{l}\text { Military } \\
\text { action in } \\
\text { Africa }\end{array}$ & $\begin{array}{l}\text { No sanctions- } \\
\text { contested policy } \\
\text { pursued (NP) }\end{array}$ & 6 & Yes & No \\
\hline $\begin{array}{l}\text { North } \\
\text { Korea }\end{array}$ & $\begin{array}{c}1950 \\
- \\
1993\end{array}$ & 2017 & $\begin{array}{l}\text { Nuclear } \\
\text { bombs } \\
\text { Missiles }\end{array}$ & $\begin{array}{c}\text { Threat and } \\
\text { imposition of } \\
\text { military } \\
\text { attack }\end{array}$ & $\begin{array}{c}\text { Sanctions- } \\
\text { contested policy } \\
\text { pursued }(\mathrm{SP})\end{array}$ & 1 & No & No \\
\hline
\end{tabular}

These cases are also summarized in Figure 1.

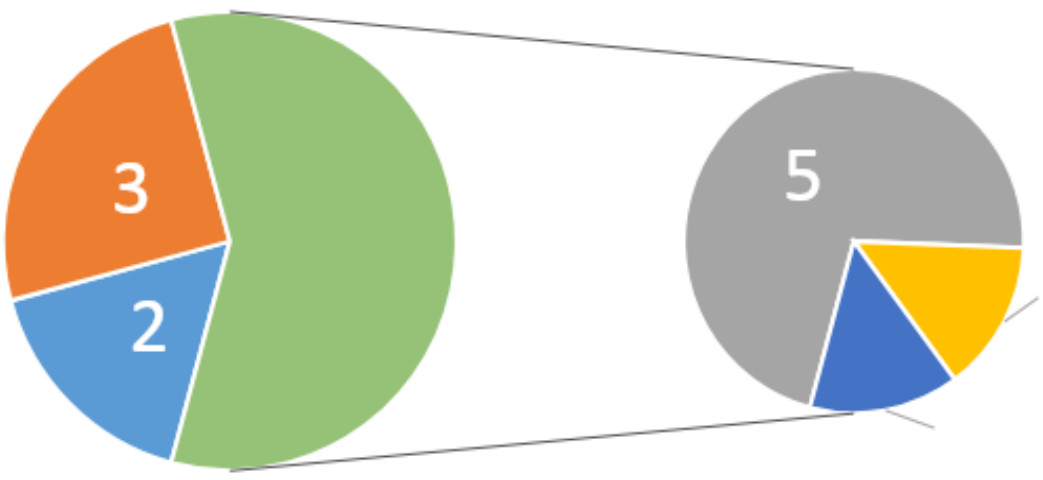

\footnotetext{
No fight-back, No sanction, No issue (NW)

No fight-back, Sanction, Issue pursued (SP)

With fight-back, No sanction, No issue (NW)

With fight-back, Issue pursued (SP)

With fight-back, No sanction, Issue pursued (NP)
}

Figure 1. Sanction cases from the standpoint of the possibility of a fight-back strategy and the current state of the sanction

With these facts in mind, the main theoretical conclusions made in the previous section are evaluated below: 


\subsection{The effects of the possibility of a fight-back strategy}

It has been observed that in none of the instances without the possibility of a countermeasure, an equilibrium in the target's favor (i.e. No sanctions- contested policy pursued (NP)) has been occurred and all cases has either led to an equilibrium "without sanctions and without the controversial policy" (NW) or continued to go on between the two sides without a steady state compromise. On the contrary, in cases where it had been possible to counteract there has been, though very few, one case in which the target had succeeded in changing the sender's strategy and reaching an equilibrium "without sanctions and with the contested policy pursued" (NP). Hence, it is inferred from the cases that although the possibility of counteracting does not necessarily lead to an agreement favored by the target, the Cuban example shows that this possibility makes the realization of such equilibrium (i.e. "No sanction with the contested policy pursued" (NP)) feasible. With a target country not able to counteract, an NP equilibrium is impossible.

Not many studies have discussed the effect of a possible countermeasure on the outcome of a sanctions regime. Banse et al have studied the effects of Russia's countermeasures in agriculture and they have calculated the effect of this policy of Russia on EU and Russian farmers. They have not discussed whether Russian counteractions is agriculture will change or have changed the sanctions' outcome, be it a lift of the sanctions or a retreat from Ukraine by the Russian troops. (Banse et al., 2019) Veebel and Markus have distinguished countermeasures as a choice for the sanctioned country (which is Russia in their study). However, they have considered this option to be one of many (options or) bids that Russia can make in a dollar-auction game model. With this in mind, they have concluded that there is a possibility that EU and US accept the status quo and Russia does not retreat from Ukraine which is consistent with our conclusion. (Veebel \& Markus, 2018a) Saparalieyev et al have recognized the role of countermeasures in the case of Russian sanctions in 2014. They enumerate those countermeasures taken by Russia but do not discuss what would happen if Russia were unable to take such measures. They predict that although Russia is able to counteract, the EU and US will continue to increase the sanctions pressure on Russia in order to make it retreat from Ukrainian conflict. This is also consistent with our findings because our model does not totally deny the possibility of a situation in which the sanctioned country retreats even in games where that sanctioned country has the option to fight-back. (Saparaliyev et al., 2019)

\subsection{The effects of being a starter}

As discussed above, in order to achieve the equilibrium, it is necessary that only one player have a contingent plan of being a starter and the other one should not be a starter. Each of the two sides that chooses this "being a starter" strategy shifts the equilibrium towards its own benefits. In order to examine this issue in the cases tabulated in the table 6, the most important developments in the chronology of the sanctions are identified and classified according to the terminology presented in the theoretic model. With regards to the importance of the Cuban sanctions case, as the only example that led to the outcome of "No sanctions with the contested policy pursued " (NP) and the Iranian cases' importance for the authors, three examples (including the Cuban sanctions since 1960, Iran's sanctions related to the occupation of the US embassy (since 1979) and Iranian sanctions related to missile and nuclear programs (since 1984)) were reviewed.

Table 7 shows that in all the three cases both the target and the sender tended to be a starter than to be a non-starter. In the first and the second case the sender and the target has changed their strategy respectively to realize an equilibrium. In the third case since no change is observed in the two players' strategy and both are starters, no equilibrium is realized till now. 
The sender and the target's actions and reaction in three cases

\begin{tabular}{|c|c|c|c|c|c|c|c|}
\hline \multirow[b]{2}{*}{ Case } & \multicolumn{3}{|l|}{ Target strategy } & \multicolumn{3}{|l|}{ Sender strategy } & \multirow{2}{*}{$\begin{array}{l}\text { Steady } \\
\text { state }\end{array}$} \\
\hline & $\begin{array}{l}\text { Total N } \\
\text { observations }\end{array}$ & $\begin{array}{l}\mathrm{P} \text { or } \mathrm{F} \\
\text { reactions }\end{array}$ & $\begin{array}{l}\text { W } \\
\text { reactions }\end{array}$ & $\begin{array}{l}\text { Total } \mathrm{P} \text { or } \mathrm{F} \\
\text { observations }\end{array}$ & $\begin{array}{l}\mathrm{S} \\
\text { reactions }\end{array}$ & $\begin{array}{l}\mathrm{N} \\
\text { reaction }\end{array}$ & \\
\hline Cuba 1960 & 6 & 6 & 0 & 16 & 11 & 5 & NP \\
\hline Iran 1979 & 2 & 2 & 0 & 7 & 7 & 0 & NW \\
\hline Iran 1984 & 7 & 6 & 0 & 135 & 131 & 4 & SP \\
\hline
\end{tabular}

The fact that whoever chooses not to be a starter, will lose the game has been also mirrored in the study of Veebel and Markus. They have modeled sanctions with a chicken game model for the case of Russian sanctions. They, in addition, have stated that the "breaking points" which both parties try to avoid determines who "pulls back" and loses the game. (Veebel \& Markus, 2016)

\subsection{The magnitude of the counteraction costs}

In the cases with the possibility of a counteraction by the target and a "no sanctions without the contested policy pursued" (NW) equilibrium, the types of these counteractions taken are diverse. On the one hand, some of these measures have not been so costly for either countries (such as the expulsion of foreign labor in the Libyan case), and on the other hand, some of them have imposed huge expenses on both sides (such as stopping oil exports in Iran and Iraq case). However, in all cases the results are the same. Therefore, the type and cost of the counteraction does not affect the result of the game.

As another evidence, it may be intuitively assumed that as the costs of the countermeasures increase, it would be more likely to see a "no sanctions with the contested policy pursued" (NP) equilibrium. Despite, in the only example of this equilibrium (i.e. the Cuban case), the cost of Cuba's military presence in Angola and Ethiopia and the rejection of American humanitarian assistance, compared with the expenses of countermeasures in other cases, such as the threat of a military attack, the discontinuation of oil exports, and missile and weapons tests is not that costly. Hence, empirical evidence does not suggest that a "no sanctions with the contested policy pursued" (NP) equilibrium is realized only if the costs of the countermeasures for the sender is high enough.

\section{CONCLUSIONS}

This article tries to explore the effects of the possibility of a fight-back strategy on the outcomes of a sanctions regime over a contested policy. It was described that if the contested policy in a sanctions regime is defined to be the primary area of interest for both the sender and the target country, there seems to be some secondary areas of interest in which the target can offend the sender's interests. These areas generally include the common interests like oil market, geopolitics of the sender's allied countries etc. If the possibility of a counteraction in a secondary area of interest is considered, the target countries are expected to use their ability to strike the sender's interest in that area and thus make the sender retreat and lift the sanctions. Hence, the main question of this article was why and how the possibility of a countermeasure may change the final outcome of a sanctions regime. This very question is not fully addressed in the sanctions literature.

Using two infinitely repeated game models and the empirical evidence in 12 sanction cases it was shown that if the sanctioned country does not have the possibility to fight-back, there is essentially no possibility of reaching an agreement in which target is not sanctioned and is allowed to pursue its disputed policy, while the power of counteracting will allow for a better deal for the target country. Of course, having the ability to counteract does not necessarily lead to a change in the equilibrium and in realization of the target's benefits. 
It was also found that an equilibrium (or practically an agreement) is reached if only one of the two sides chooses to be a starter. Whoever abandons being a starter literally "loses" the sanctions game. This led to an additional conclusion which argues that state in which the sanctions are kept imposed and the contested policy also continues to be pursued is not an equilibrium and thus it is not a possible agreement. Moreover, the theoretical model and the empirical evidence showed that the counteraction costs do not have any effect on the games' equilibria.

Finally, it was found that in order for the sender to force the target retreat, the sanction costs for the target must be greater than the utility realized by pursuing the contested policy. This means the sender would have to introduce severe sanctions if it wants to bring the balance of the game to an equilibrium with "no sanctions and no disputed policy"

There were some limitations doing the research for this paper. First, in order to evaluate the theoretical results, there was access to a limited number of sanctions' case studies the story of which has been published comprehensively and in a chronological order. More detailed research on the history of events in more sanction cases could help us investigate whether there has been a possibility to countermeasure and what the results has been. That, in turn, could make the conclusions made above more reliable. Second, there was not the possibility to discuss the reliability of theoretical insight using quantitative methods. That was because, the sanctions' data bases has not yet considered the existence of a probable fight back strategy as an attribute for sanction cases and thus this has not been codified. That is why no quantitative empirical study can be made on this issue.

Some topics and areas of research can be suggested for future work:

1. The codified sanction cases' databases especially TIES can be updated by including the following parameters in every sanction case:

i) The possibility of countermeasure in a secondary area of interest

ii) If it has been possible, whether the target country has taken that countermeasure or not

iii) The importance of the secondary area of interest for both parties

2. The role of a third player (a third country for example) can be included in the game model. This player may have the option to neutralize the fight back strategy taken by the target or amplify that strategy.

The theoretical results can be improved in terms of accuracy, if the complete information assumption is relaxed. The model presented here can be reworked using an infinitely repeated game with incomplete information.

\section{REFERENCES}

Afesorgbor, S. K. (2019). The impact of economic sanctions on international trade: How do threatened sanctions compare with imposed sanctions? European Journal of Political Economy, 56, 11-26.

Banse, M., Duric, I., Götz, L., \& Laquai, V. (2019). From the Russian food import ban to free trade from Lisbon to Vladivostok - will farmers benefit? Journal of International Studies, 12(4), 20-31. https://doi.org/10.14254/2071$8330.2019 / 12-4 / 2$

Bimbetove, B., Tyurina, Y., Troyanskaya, M., Ermakova, E., Orynbassarova, A., Skakova, A., ... Agabekova, G. (2019). The impact of international sanctions on national economic regime of target states. Academy of Strategic Management Journal, 18(4), 1-9.

Brown, M. (2019). The Art of Sanctions: A Game Theoretic Approach to Sanctions Against the Powerful. Texas Chistian University. Retrieved from https://repository.tcu.edu/handle/116099117/27046

Chen, Y. E., Fu, Q., Zhao, X., Yuan, X., \& Chang, C.-P. (2019). International sanctions' impact on energy efficiency in target states. Economic Modelling, 82, 21-34. 
Dong, Y., \& Li, C. (2018). Economic sanction games among the US, the EU and Russia: Payoffs and potential effects. Economic Modelling, 73, 117-128. https://doi.org/10.1016/j.econmod.2018.03.006

Drezner, D. W. (1999). The Sanction Paradox, Economic Statecraft and International Relations (Vol. 1). Cambridge: Cambridge University Press.

Eaton, J., \& Engers, M. (1992). Sanctions. Journal of Political Economy, 100(5), 899-928.

Eaton, J., \& Engers, M. (1999). Sanctions: Some simple analytics. American Economic Review, 89(2), 409-414. https://doi.org/10.1257/aer.89.2.409

Gharibnavaz, M. R., \& Waschik, R. (2018). A computable general equilibrium model of international sanctions in Iran. World Economy, 41(1), 287-307. https://doi.org/10.1111/twec.12528

Han, B. (2018). The role and welfare rationale of secondary sanctions: A theory and a case study of the US sanctions targeting Iran. Conflict Management and Peace Science, 35(5), 474-502. https:/ / doi.org/10.1177/0738894216650836

Hellquist, E. (2016). Either with us or against us? Third-country alignment with EU sanctions against Russia/Ukraine. Cambridge Review of International Affairs, 29(3), 997-1021.

Hufbauer, G. C., Schott, J. J., \& Elliott, K. A. (2007). Economic sanctions reconsidered. Peterson Institute For International Economics (Vol. 35). https://doi.org/10.1017/CBO9781107415324.004

Jeong, J. M. (2018). Do sanction types affect the duration of economic sanctions? The case of foreign aid. International Political Science Review, 40(2), 231-245.

Jing, C., Kaempfer, W. H., \& Lowenberg, A. D. (2003). Instrument choice and the effectiveness of international sanctions: a simultaneous equations approach. Journal of Peace Research, 40(5), 519-535. https://doi.org/10.1177/00223433030405002

Kaempfer, W. H., \& Lowenberg, A. D. (1988). The theory of international economic sanctions: A public choice approach. The American Economic Review, 78(4), 786-793. Retrieved from http://www.jstor.org/stable/1811175

Kaempfer, W. H., \& Lowenberg, A. D. (2007). Chapter 27 The Political Economy of Economic Sanctions. Handbook of Defense Economics, 2(06), 867-911. https://doi.org/10.1016/S1574-0013(06)02027-8

Kavaklı, K., Chatagnier, J. T., \& Hatipoğlu, E. (2020). The Power to Hurt and the Effectiveness of International Sanctions. The Journal of Politics, 82(3).

Lacy, D., \& Niou, E. (2004). A Theory of Issue Linkage and Economic Sanctions: The Roles of Information, Preferences, and Threats. Journal of Politics, 66(1), 25-42.

Lam, S. L. (1990). Economic sanctions and the success of foreign policy goals. A critical evaluation. Japan and The World Economy, 2(3), 239-248. https://doi.org/10.1016/0922-1425(90)90003-B

Lektzian, D., \& Souva, M. (2001). Institutions and international cooperations: An event hisorty analysis of the effects of economic sanctions. Journal of Conflict Resolution, 45(1), 61-79. https://doi.org/0803973233

Lohmann, S. (2016). The convergence of transatlantic sanction policy against Iran. Cambridge Review of International Affairs, 29(3), 930-951. Retrieved from https://www.tandfonline.com/doi/full/10.1080/09557571.2016.1166479

McCormack, D., \& Pascoe, H. (2015). Sanctions and Preventive War. Journal of Conflict Resolution, 0022002715620471. https://doi.org/10.1177/0022002715620471

McLean, E. V., \& Whang, T. (2010). Friends or foes? major trading partners and the success of economic sanctions. International Studies Quarterly, 54(2), 427-447. https://doi.org/10.1111/j.1468-2478.2010.00594.x

Morgan, T. C., \& Bapat, N. A. (2003). Imposing Sanctions : States , Firms , and Economic Coercion. International Studies Review, 5(4), 65-79.

Morgan, T. C., Bapat, N., \& Kobayashi, Y. (2014). Threat and imposition of economic sanctions 1945-2005: Updating the TIES dataset. Conflict Management and Peace Science. https://doi.org/10.1177/0738894213520379

Onder, M. (2020). Regime type, issue type and economic sanctions: The role of domestic players. Economies, 8(1). https://doi.org/10.3390/economies8010002

Peksen, D. (2019, September 19). When Do Imposed Economic Sanctions Work? A Critical Review of the Sanctions Effectiveness Diterature. Defence and Peace Economics. Routledge. https://doi.org/10.1080/10242694.2019.1625250

Portela, C. (2016). Are European Union sanctions "targeted "? Cambridge Review of International Affairs, 29(3), $912-929$. Retrieved from https://www.tandfonline.com/doi/abs/10.1080/09557571.2016.1231660 
Rapelanoro, N., \& Bali, M. (2020). International Economic Sanctions : Multipurpose Index Modelling in the Ukrainian Crisis Case. EconomiX.

Salman, Z., Shin, S.-H., \& Shin, Y.-J. (2019). An Analysis by Window DEA on the Influence of International Sanction to the Efficiency of Iranian Container Ports. The Asian Journal of Shipping and Logistics, 35(4), 163-171.

Saparaliyev, D., Mokin, C., Movkebayeva, G., Saiymova, M., \& Mustafina, A. (2019). Review and analysis of imposed European Union and United States international sanctions on Ukrainian crisis and Russia's countermeasures. Journal of Legal, Ethical and Regulatory Issues, 22(2), 1-12.

Shadiqi, K., \& Pradiptyo, R. (2011). A game theoretical analysis of economic sanction. Munich Personal RePEc Archive.

Simon, M. V. (1995). When sanctions can work: Economic sanctions and the theory of moves. International Interactions, 21(3), 203-228. https://doi.org/10.1080/03050629508434866

Spaniel, W., \& Smith, B. C. (2015). Sanctions, Uncertainty, and Leader Tenure. International Studies Quarterly, 59(4), 735749. https://doi.org/10.1111/isqu.12199

Taehee Whang. (2010). Structural estimation of economic sanctions: From initiation to outcomes. Journal of Peace Research, 47(5), 561-573. https://doi.org/10.1177/0022343310376868

Tsebelis, G. (1990). Are Sanctions Effective ? A Game-Theoretic Analysis. The Journal of Conflict Resolution, 34(1), 3-28.

Tyll, L., Pernica, K., \& Arltová, M. (2018). The impact of economic sanctions on russian economy and the RUB/USD exchange rate. Journal of International Studies, 11(1), 21-33. https://doi.org/10.14254/2071-8330.2018/11-1/2

UN Targeted Sanctions Qualitative Database. (2014).

Veebel, V., \& Markus, R. (2016). Will sanctions against Russia be successful: Will Russia fall before Ukraine? Journal of Security and Sustainability Issues, 5(4), 465-480. https://doi.org/10.9770/jssi.2016.5.4(2)

Veebel, V., \& Markus, R. (2018a). Forcing Russia to respect minsk protocols with dollar auction-game model. Journal of International Studies, 11(3), 9-20. https://doi.org/10.14254/2071-8330.2018/11-3/1

Veebel, V., \& Markus, R. (2018b). The bust, the boom and the sanctions in trade relations with Russia. Journal of International Studies, 11(1), 9-20. https://doi.org/10.14254/2071-8330.2018/11-1/1

Whang, T., \& Kim, H. J. (2015). International Signaling and Economic Sanctions. International Interactions, 41 (3), $427-$ 452. https://doi.org/10.1080/03050629.2015.1024242

Whang, T., Mclean, E. V., \& Kuberski, D. W. (2013). Coercion, Information, and the Success of Sanction Threats. American Journal of Political Science, 57(1), 65-81. https://doi.org/10.1111/j.1540-5907.2012.00629.x 